This is the author's manuscript for publication. The publisher-formatted version may be available through the publisher's web site or your institution's library.

\title{
Applications of discrete element method in modeling of grain postharvest operations
}

\author{
J. M. Boac, R. P. K. Ambrose, M. E. Casada, R. G. Maghirang, and D. E. Maier
}

How to cite this manuscript

If you make reference to this version of the manuscript, use the following information:

Boac, J. M., Ambrose, R. P. K., Casada, M. E., Maghirang, R. G., \& Maier, D. E. (2014). Applications of discrete element method in modeling of grain postharvest operations. Retrieved from http://krex.ksu.edu

\section{Published Version Information}

Citation: Boac, J. M., Ambrose, R. P. K., Casada, M. E., Maghirang, R. G., \& Maier, D. E. (2014). Applications of discrete element method in modeling of grain postharvest operations. Food Engineering Reviews, 6(4), 128-149.

Copyright: @ Springer Science+Business Media New York 2014

Digital Object Identifier (DOI): doi:10.1007/s12393-014-9090-y

Publisher's Link: http://link.springer.com/article/10.1007/s12393-014-9090-y

This item was retrieved from the K-State Research Exchange (K-REx), the institutional repository of Kansas State University. K-REx is available at http://krex.ksu.edu 


5

\section{6} 17

5

\title{
ApPlications of Discrete Element Method In MOdeling OF Grain PostharVEST OPERATIONS
}

\author{
J. M. Boac, R. P. K. Ambrose, M. E. Casada, R. G. Maghirang, and D. E. Maier
}

Authors:

Josephine M. Boac, Ph.D., Postdoctoral Fellow, Department of Grain Science and Industry, Kansas State University, Manhattan, Kansas;

R. P. Kingsly Ambrose, Ph.D., Assistant Professor, Department of Grain Science and Industry, Kansas State University, Manhattan, Kansas;

Mark E. Casada, Ph.D., Research Agricultural Engineer, USDA-ARS Center for Grain and Animal Health Research, Engineering and Wind Erosion Research Unit, Manhattan, Kansas;

Ronaldo G. Maghirang, Ph.D., Professor, Department of Biological and Agricultural Engineering, Kansas State University, Manhattan, Kansas; and

Dirk E. Maier, Ph.D., Professor and Department Head, Department of Grain Science and Industry, Kansas State University, Manhattan, Kansas.

Corresponding author:

R. P. Kingsly Ambrose, Department of Grain Science and Industry, Kansas State University, 312 Shellenberger Hall, Manhattan, Kansas; phone: 785-532-4091; fax: 785-532-7010; e-mail: kingsly@ksu.edu. 
Abstract. Grain kernels are finite and discrete materials. Although flowing grain can behave

27 like a continuum fluid at times, the discontinuous behavior exhibited by grain kernels cannot be simulated solely with conventional continuum-based computer modeling such as finite-element or finite-difference methods. The discrete element method (DEM) is a proven numerical method that can model discrete particles like grain kernels by tracking the motion of individual particles. DEM has been used extensively in the field of rock mechanics. Its application is gaining popularity in grain postharvest operations, but it has not been applied widely. This paper reviews existing applications of DEM in grain postharvest operations. Published literature that uses DEM to simulate postharvest processing is reviewed, as are applications in handling and processing of grain such as soybean, corn, wheat, rice, rapeseed, and the grain coproduct distillers dried grains with solubles (DDGS). Simulations of grain drying that involve particles in both free-flowing and confined-flow conditions are also included. Review of existing literature indicates that DEM is a promising approach in the study of the behavior of deformable soft particulates such as grain and coproducts and it could benefit from the development of improved particle models for these complex-shaped particles.

Keywords Discrete element method, grain handling, grain processing, free-flowing grain, confined grain 


\section{Introduction}

Grain kernels are considered finite and discrete materials. At times, flowing grain can behave like a continuum fluid or a collection of individual interacting particles depending, in large part, on the energy imparted to the grain kernels (de Bruyn 2012). Granular materials such as cereal grains that exhibit discontinuous behavior cannot be simulated solely using conventional continuum-based modeling techniques such as finite-element or finite-difference methods. Examples of processes dominated by discontinuum behavior include flow of bulk solids in hoppers, feeders, chutes, screens, crushers, ball mills, mixers, and conveyor systems. Micromechanical behavior of particular media, stability of underground mine openings, stability of rock slopes, and mineral processing are other solids handling or processing examples in which continuum theory may be inapplicable (Dewicki 2003).

Williams et al. (1985) described the discrete element method (DEM) to numerically solve problems involving discrete elements like grain kernels. The DEM belongs to a family of numerical modeling techniques designed to solve problems in engineering and applied science that display gross discontinuous behavior (Hustrulid and Mustoe 1996; Hustrulid 1998; Dewicki 2003). DEM can analyze multiple, interacting, deformable, discontinuous, or fractured bodies undergoing rotations and large displacements. The basic assumption in DEM is that every discrete element has distinct boundaries that physically separate it from every other element in the analysis. Basic equations of elasticity are written under an inertial frame then transferred to a non-inertial frame, which is translating and rotating. This is performed so that to an observer in the non-inertial frame, i.e., the new frame, the object exhibits no mean translation or rotation. The deformation can then be decoupled from the mean motion and written as the sum of the bodies' normal modes, which in turn gives a newly derived set of decoupled modal equations. 
These equations are applied on an element-by-element basis, and the elements communicate through boundary forces. The decoupled equations are then solved by an explicit central difference scheme, and the final solution is obtained by means of modal superposition (Williams et al. 1985).

Cundall and Strack (1979), who were the first to publish this technique, defined DEM as a numerical model capable of describing the mechanical behavior of assemblies of discs and spheres. The model is based on an explicitly numerical scheme in which the particle interaction is monitored at each contact, and the particle motion is modeled particle by particle. Figure 1 illustrates a schematic overview of the sequence of calculations involved in DEM simulation using the central difference, distinct element method proposed by Cundall and Strack (1979). In DEM modeling, particle interaction is treated as a dynamic process, which assumes that equilibrium states develop whenever internal forces in the system balance (Theuerkauf et al. 2007). Contact forces and displacements of a stressed particle assembly are obtained by tracking the motion of individual particles. Motion results from disturbances that propagate through the assembly. The mechanical behavior of the system is described by the motion of each particle and the force and moment acting at each contact. Zhu et al. (2007) also mentioned that DEM simulations can provide dynamic information, such as trajectories of, and transient forces acting on, individual particles, which is extremely difficult or impossible to obtain by physical experimentation at this stage of development. Thus, DEM has been used increasingly to study the particle mechanics in solids handling and processing applications. A complete description of the DEM can be found in Williams et al. (1985), Cundall (1988b), Hart et al. (1988), and Cundall and Hart (1989). 
DEM application is gaining popularity in postharvest processing of grain and food products because of its close characterization of actual conditions in predicting various processes. Unlike the field of mining and the chemical industry, however, DEM is not being widely applied because of various particle property issues arising from the biological origins of grain and food products. The objective of this paper is to review existing published research that used DEM as the numerical modeling technique in postharvest grain handling and processing. The scope of this paper is limited to DEM applications on grain and its coproducts.

\section{Theoretical Background of DEM}

\section{Approaches in DEM Modeling}

Two types of DEM techniques are most common: hard-sphere and soft-sphere approaches.

These approaches are differentiated by how the deformation during collision or contact is

represented. The hard-sphere approach does not allow deformation or interpenetration during

impact (Hoomans et al. 1996), whereas the soft-sphere approach does (Zhu et al. 2007;

O”Sullivan 2011a, 2011b). The hard-sphere approach is at the basis of the collisional or eventdriven (ED) models. The ED models are also categorized as non-smooth DEM, which models the shocks between particles by means of shock laws with restitution coefficient (Fortin et al. 2004). The strategy with ED models is to start with equations governing momentum exchange, which contrasts with the soft-sphere approach that solve the equations governing the linear and angular motion of the colliding or contacting particles (O'Sullivan 2011b). With the hard-sphere approach the time step interval for the numerical solution varies with the time between each collision. In contrast, the soft-sphere approach uses a constant time step interval in the solutions. The ED method is limited to circular or spherical particles, takes into account collisions or shocks between two colliding particles only, and does not consider multiple contacts (Fortin et 
113

114

115

116

117

118

119

120

121

122

123

124

125

126

127

128

129

130

131

132

133

134

135

al. 2004). A sequence of instantaneous collisions is processed, one collision at a time, and the forces between particles often are not explicitly considered (Zhu et al. 2007); therefore, the hardsphere approach or the ED method is typically most useful in rapid granular flow simulations, where the granular material is not dense because it has been partially or completely fluidized (O’Sullivan 2011b). The hard-sphere approach is computationally cheap and, therefore, may be preferred for non-dense flow. However, Delaney et al. (2007) argued that this approach, although computationally faster, falls short in describing the details of the dense material's response involving multiple simultaneous contacts.

Fortin et al. (2004) developed an improved non-smooth DEM based on non-smooth contact dynamics (NSCD). The NSCD method models the contact between particles with the Coulomb unilateral contact law with dry friction and takes into account multiple contacts and shocks between particles (Jean and Moreau 1991). Fortin et al. (2004) improved the NSCD by overcoming the difficulties that arise in using the dry friction modeled by Coulomb's law, which is typically non-associated (i.e., during the contact, the sliding vector is not normal to the friction cone). They used bi-potential theory, which leads to a fast predictor-corrector scheme involving just an orthogonal projection onto the friction cone and allows using a convergence criterion based on an error estimator in the constitutive law. According to O'Sullivan (2011b), the contact dynamics method is not strictly under the hard- or soft-sphere approaches; they are sometimes referred to as rigid body dynamics.

Cundall and Strack (1979) originally developed the soft-sphere method, which was the first discrete numerical modeling technique published in the literature. Particles in the soft-sphere approach are also rigid but they are permitted to overlap at the contact points as a representation of the deformation that occurs at the contacts (Zhu et al. 2007; O'Sullivan 2011a, 2011b). These 
deformations are used to calculate elastic, plastic, and frictional forces between particles; the motion of particles is described by Newton's laws of motion. The major advantage of soft-sphere models is that they are capable of handling multiple particle contacts, which is important when modeling quasi-static systems (Zhu et al. 2007).

Advantages of the soft-sphere approach in modeling dense-phase bulk granular materials were also highlighted by Campbell (2006). He emphasized that dense granular materials (as opposed to those fluidized or in dilute phase) in bulk are soft because their sound speed is approximately 50 times slower than those of their constituent solid materials and the bulk has an apparent elastic modulus more than three orders of magnitude smaller than its constituent solid. He added that dense systems interact by force chains (which are quasi-liner structures that support the bulk of the internal stress within the material) and transmit force along the chain by elastically deforming the interparticle contacts. Modeling such systems as rigid spheres and any other model would miss essential physics (Campbell 2006). He also mentioned that particle surface friction is essential to modeling dense systems because removing it can cause transition between an elastic and inertial flow regime. Surface friction is important to the strength of the force chains and force chains are vital to the elastic flow regimes, thus, friction is also essential physics required in the simulation to avoid erroneous behavior.

The soft-sphere approach, with the advantages listed above for describing the bulk material physics, is most commonly used in the grain and food-processing industries. Thus, soft-sphere DEM modeling is the focus of this review.

\section{Governing Equations of Motion}

$$
\text { In soft-sphere DEM, contact forces and displacements of the particle assembly are computed }
$$

$$
\text { by tracking the motion of each individual particle using an explicit numerical scheme and a very }
$$


small time step (Cundall and Strack, 1979). The process uses Newton's laws of motion that gives

160

161

$162 \quad m_{i} \frac{d v_{i}}{d t}=\sum_{j}\left(F_{n_{i j}}+F_{t_{i j}}\right)+m_{i} g$

$163 \quad I_{i} \frac{d \omega_{i}}{d t}=\sum_{j}\left(R_{i} \times F_{t_{i j}}\right)+\tau_{i j}$

164 where $m_{i}, R_{i}, v_{i}, \omega_{i}$, and $I_{i}$ are the mass, radius, linear velocity, angular velocity, and moment of

165 inertia of particle $i$, respectively; $F_{n_{i j}}, F_{t_{i j}}$, and $\tau_{i j}$ are the normal force, tangential force, and

166 torque acting on particles $i$ and $j$ at contact points, respectively; $g$ is the acceleration due to

167 gravity; and $t$ is the time.

\section{Modeling of Contact Forces}

Force-displacement laws at contact points can be represented by different contact models. The wide range of contact models and their corresponding equations are not discussed in detail in this review. Zhu et al.'s (2007) summarizes various contact force models as well as non-contact force models used in discrete particle simulations. O'Sullivan (2011b) also gives detailed discussions of contact models in her book.

The simplest contact model commonly used is the linear spring-dashpot model (Cundall and Strack 1979), in which the spring stiffness is assumed to be constant (Mishra 2003). An improvement to the linear contact model employs the Hertz theory to obtain the force deformation relation for the contact (e.g., nonlinear-spring dashpot model). Unlike the linear contact model, the Hertzian contact law considers that normal stiffness varies with the amount of overlap. This approach has been extended to cases in which colliding bodies tend to deform (constrained plastic deformation). Numerical models of interaction at the contact involve the 
181 force-deformation equation, which is augmented with a damping term to reflect dissipation in the 182 contact area.

183 One model to represent the force-displacement laws at the contacts is the Hertz-Mindlin 184 contact model (Mindlin 1949; Mindlin and Deresiewicz 1953; Tsuji et al. 1992; Di Renzo and Di 185 Maio 2004, 2005). This non-linear model features both the accuracy and simplicity derived from 186 combining the Hertz theory in the normal direction and the Mindlin model in the tangential 187 direction (Tsuji et al. 1992; Remy et al. 2009). Forces on the particles at contact points include 188 contact force and viscous contact damping force (Zhou et al. 2001). These forces were calculated 189 by assuming the presence of elastic springs and dashpots in the normal (n) and tangential (t) 190 directions (Figure 2).

191 The normal force, $F_{n}$, is given as follows (Tsuji et al. 1992; Remy et al. 2009):

$192 \quad F_{n}=-K_{n} \delta_{n}^{3 / 2}-\eta_{n} \dot{\delta}_{n} \delta_{n}^{1 / 4}$

193 where $K_{n}$ is the normal stiffness coefficient; $\delta_{n}$ is the normal overlap or displacement; $\dot{\delta}_{n}$ is the 194 normal velocity; and $\eta_{n}$ is the normal damping coefficient.

195 The tangential force, $F_{t}$, is governed by the following equation (Tsuji et al. 1992; Remy et al. 196 2009):

$197 \quad F_{t}=-K_{t} \delta_{t}-\eta_{t} \dot{\delta}_{t} \delta_{n}^{1 / 4}$

198 where $K_{t}$ is the tangential stiffness coefficient; $\delta_{t}$ is the tangential overlap; $\dot{\delta}_{t}$ is the tangential 199 velocity; and $\eta_{t}$ is the tangential damping coefficient. The tangential overlap is calculated by 200 (Remy et al 2009):

$201 \quad \delta_{t}=\int v_{r e l}^{t} d t$ 
where $v_{r e l}^{t}$ is the relative tangential velocity of colliding particles and is defined by (Remy et al.

203

204

205

206

207

208

209

210 2009):

$$
v_{r e l}^{t}=\left(v_{i}-v_{j}\right) \cdot s+\omega_{i} R_{i}+\omega_{j} R_{j}
$$

where $s$ is the tangential decomposition of the unit vector connecting the center of the particle.

In addition, a tangential force is limited by Coulomb friction $\left(\mu_{s} F_{n}\right)$, where $\mu_{s}$ is the coefficient of static friction. When necessary, rolling friction can be accounted for by applying a torque to contacting surfaces. The rolling friction torque, $\tau_{i}$, is given by (DEM Solutions 2013; Remy et al. 2009):

$$
\tau_{i}=-\mu_{r} F_{n} R_{0} \omega_{0}
$$

where $\mu_{r}$ is the coefficient of rolling friction, $R_{0}$ is the distance of the contact point from the center of the mass, and $\omega_{0}$ is the unit angular velocity vector of the object at the contact point (Tsuji et al. 1992; Di Renzo and Di Maio 2004; Li et al. 2005; DEM Solutions 2013; Remy et al. 2009).

\section{Stiffness and Damping Coefficient}

After modeling the contact forces, the next step is to determine the values of stiffness, $K$, damping coefficient, $\eta$, and friction coefficient, $\mu$. The friction coefficient is measurable and considered a parameter obtained empirically. The damping coefficient can be computed from stiffness. Thus, the stiffness is the parameter which must be determined first and can be computed by Hertzian contact theory when the physical properties such as Young's modulus and Poisson ration are known (Tsuji et al. 1992).

Following the Hertz-Mindlin contact model above, the normal stiffness and normal damping coefficients are (Tsuji et al. 1992; Remy et al. 2009): 
$224 \quad K_{n}=\frac{4}{3} E^{*} \sqrt{R^{*}}$

$$
\eta_{n}=\frac{\ln e}{\sqrt{\ln ^{2} e+\pi^{2}}} \sqrt{m^{*} K_{n}}
$$

226 where $E^{*}$ is the equivalent Young's modulus, $R^{*}$ is the equivalent radius, $m^{*}$ is the equivalent

227 mass, and $e$ is the coefficient of restitution. Equivalent properties $\left(R^{*}, m^{*}\right.$, and $\left.E^{*}\right)$ during

228 collision of particles with different materials such as particles $i$ and $j$ are defined as (Di Renzo

229 and Di Maio 2004; DEM Solutions 2013):

$230 \quad R^{*}=\left(\frac{1}{R_{i}}+\frac{1}{R_{j}}\right)^{-1}$

$231 \quad E^{*}=\left(\frac{1-v_{i}^{2}}{E_{i}}+\frac{1-v_{j}^{2}}{E_{j}}\right)^{-1}$

$232 \quad m^{*}=\left(\frac{1}{m_{i}}+\frac{1}{m_{j}}\right)^{-1}$

233 where $v$ is the Poisson's ratio (Di Renzo and Di Maio 2004; DEM Solutions 2013). Similarly, for

234 a collision of a sphere $i$ with a wall $j$, the same relations apply for Young's modulus $E^{*}$, whereas

$235 R^{*}=R_{i}$ and $m^{*}=m_{i}$.

236 Tangential stiffness and tangential damping coefficients are defined as follows (Tsuji et al.

237 1992; DEM Solutions 2013; Remy et al. 2009):

$238 \quad K_{t}=8 G^{*} \sqrt{R^{*} \delta_{n}}$

$239 \quad \eta_{t}=\frac{\ln e}{\sqrt{\ln ^{2} e+\pi^{2}}} \sqrt{m^{*} K_{t}}$

240 where $G^{*}$ is the equivalent shear modulus defined by (Li et al. 2005):

$241 \quad G^{*}=\left(\frac{2-v_{i}}{G_{i}}+\frac{2-v_{j}}{G_{j}}\right)^{-1}$

$242 G_{i}$ and $G_{j}$ are shear moduli of particles $i$ and $j$, respectively. 
$260 \quad t_{c}=\frac{\pi \bar{R}}{\beta} \sqrt{\frac{\rho_{p}}{G}}$

\section{Critical Time Step}

For dynamic processes, important factors to consider are the propagation of elastic waves across the particles, the time for load transfer from one particle to adjacent contacting particles, and the energy transmission across a system that should not be faster than in nature (Li et al. 2005). In the non-linear contact model (e.g., Hertzian), the critical time increment or critical time step cannot be calculated beforehand, unlike the linear contact model in which the critical time step is related to the ratio of contact stiffness to particle density. Miller and Pursey (1955), however, showed that Rayleigh waves or surface waves account for $67 \%$ of the radiated energy, whereas dilational or pressure waves and distortional or shear waves are $7 \%$ and $26 \%$, respectively, of the radiated energy. Thus, it is assumed that all of the energy is transferred by the Rayleigh waves because the speed difference between the Rayleigh wave and the distortional wave is small, and the energy transferred by the dilational wave is negligible (Li et al. 2005). Moreover, the average time of arrival of the Rayleigh wave at any contact remains the same irrespective of the contact point location. For simplicity, the critical time step is based on the average particle size, and a fraction of this is used in the simulations ( $\mathrm{Li}$ et al. 2005; DEM Solutions 2013). The critical time step is given by the following equation (Li et al. 2005; DEM Solutions 2013):

where $\bar{R}$ is the average particle radius, $\rho_{p}$ is the particle density, $G$ is the particle shear modulus, and $\beta$ can be approximated by (Li et al. 2005):

$$
\beta=0.8766+0.163 v
$$

A major concern in using the DEM is the computational time because of the calculation of particle interactions and spatial movement at very small time steps. Boukouvala et al. (2013) 
developed the Discrete Element- Reduced- Order Modeling (DE-ROM) approach to reduce computational time. The authors used principal component analysis (PCA) based on the data decomposition approach for discrete simulation and validated the new approach by studying a mixing process. Although this approach is encouraging, it requires data pre-processing to identify the optimal discretization based on the geometry and the state variable variability. This recently published work has not been adapted in grain postharvest operation modeling.

\section{Particle Models - Grain and its Coproducts}
The choice of shape representation for modeling particles is critical to the accuracy of real particle behavior during simulation, contact detection, and computation for contact forces determination (Hogue 1998; Favier et al. 1999). The earliest particle models were twodimensional (2-D) and of circular (Cundall and Strack 1979) or polygonal shapes (Walton 1983). Later developments extended representations to three-dimensional (3-D) shapes, using spheres (Cundall 1988a), polyhedra (Cundall 1988b; Hocking 1992), ellipses (Ting et al. 1993), ellipsoids (Lin and Ng 1997), superquadric functions (Williams and Pentland 1989; Hogue 1998), multi-element axi-symmetrical non-spherical particles (Favier et al. 1999), and bonded particles (Potyondy and Cundall 2004; Metzger and Glasser 2013). Although contact detection and computation time are very important, the critical objective in DEM modeling is accurate simulation of the behavior of an assembly of real particles (Favier et al. 1999). Favier et al. (1999) also mentioned that the influence of particle shape on predicted behavior is less documented than the relationship between shape and the efficiency of contact detection, with the exception of particle models that used polyhedral shapes (Hart et al., 1988; Ghaboussi and Barbosa, 1990). In the following sections, the particle models developed and used for predicting 
handling and processing behavior of cereal grains, oilseeds, and their coproducts are explored and summarized in Table 1.

\section{Soybeans}

Soybean is one of the major oilseeds produced around the world. Like any other agricultural grain, the physico-chemical properties of soybeans and their products depend on the place of origin and processing methods. Soybean-handling systems and processing operations have been simulated for the past 20 years in an effort to optimize processes. LoCurto et al. (1997) used a particle model for soybeans consisting of a cluster of four spheres of equal radius, with centers lying on a plane. This was similar to Favier et al.'s (1999) representation of non-spherical particles comprising overlapping spheres with centers fixed in a position relative to each other along the major axis of the particle's symmetry. The 3-D four-sphere particle model was used to simulate the behavior of a single soybean kernel bouncing in aluminum, glass, and acrylic surfaces to measure the coefficient of restitution. The simulations predicted the coefficient of restitution with reasonable accuracy. Vu-Quoc et al. (2000) created a soybean particle model based on the multi-sphere method developed by Favier et al. (1999) to predict the dry granular flow of soybean in a chute.

Soybean kernels resemble a sphere with high average sphericity values of above 0.8 (Isik 2007); thus, to reduce computation times, single spheres were used by most researchers to simulate bulk soybean characteristics. Li et al. (2002) simulated the separation of soybeans and mustard seeds in a sieve using 2-D DEM and modeling soybeans as circular discs. They used a linear spring model and modified their codes by conducting trial runs to select the appropriate time step for the simulations. Both kernels (soybeans and mustard seeds) were assumed to have uniform particle size. The screen wire was also modeled in DEM using a group of circular 
311 particles that had the properties of the screen wires, and these particles were vibrated to simulate

312 the movement of a mechanically agitated screen. The authors found that the two spherical

313 particle models representing soybeans and mustard seeds in a screening process were adequate

314 and that the DEM simulation can provide the critical feeding rate for the most effective screening

315 operation. Boac et al. (2010) used a single sphere particle model to simulate bulk soybean

316 property testing using EDEM (DEM Solutions, Ltd., Edinburgh, UK), a commercial DEM code.

317 The researchers used a no-slip Hertz-Mindlin contact to simulate and model the bulk density and

318 angle of repose measurement tests. They conducted this simulation to develop a particle model

319 with appropriate parameter combinations of coefficients of restitution, static friction, rolling

320 friction, particle size distribution, and particle shear modulus that best matched the property

321 values available in the literature. The developed soybean particle model was then used to

322 simulate the commingling of two soybean lots, with different intrinsic properties, in a bucket-

323 type grain elevator boot system (Boac et al. 2012).

324 Corn

325 Corn is a cereal grain that is grown widely throughout the world and is a major food grain in

326 Africa and Latin America, with the United States as its largest producer. In the U.S., almost $85 \%$

327 of corn produced is used as livestock feed and as a raw material for industrial products (FAO,

328 2013). The design and development of processing and handling equipment for corn is a mature

329 area, but because of the volume of grain handled and the new varieties that are being developed

330 and to mitigate dust issues, particle modeling is being used to improve the design of equipment.

331 Chung and Ooi (2006, 2008a, 2008b) modeled corn kernels using overlapping spheres to match

332 the measured average major, intermediate, and minor dimensions. They used Particle Flow Code

333 (PFC) 3D (Itasca Consulting Group, Inc., Minneapolis, MN), a commercial DEM code, to 
334 simulate a confined compression and rod penetration in a dense granular medium (Chung and

335 Ooi 2006; 2008a) and silo discharging (Chung and Ooi 2008b). The authors used a four-sphere

336 particle representation for corn because increasing the number of spheres in a single particle

337 leads to additional computational cost (Chung and Ooi 2006). Measured material properties

338 (Chung et al. 2004) were used for simulation purposes.

339 Modeling corn particles using overlapping discs called clumps in PFC 2D also has been

340 employed in the development of particle models (Coetzee and Els (2009a, 2009b, 2009c). A

341 clump is a single entity composed of two or more overlapping spheres (in 3-D) and discs (in 2-

342 D) to form one rigid particle. Internal contact forces between the overlapping spheres or discs are

343 ignored in calculations (Lu and McDowell 2007). Clumps do not break during simulations

344 regardless of the forces acting upon them (Itasca 2008; Ferellec and McDowell 2010). Coetzee

345 and Els (2009a, 2009b, 2009c) used this 2-D-clump corn particle model to calibrate material

346 parameters such as the particle internal friction angle using laboratory shear tests and particle

347 stiffness using compression tests. They validated the calibration process by modeling silo

348 discharge and bucket filling. Coetzee et al. (2010) extended these studies to DEM modeling of

349 dragline bucket filling using particle models comprising two to four overlapping spheres that

350 represent crushed rocks.

351 The highest number of spheres used to develop a corn particle model was simulated by

352 Gonzalez-Montellano et al. (2011, 2012a, 2012b). They modeled corn kernels consisting of six

353 spheres using the multi-spheres method (Favier et al. 1999) and experimentally derived material

354 property values (Gonzalez-Montellano et al. 2012c). The authors indicated that using more than

355 six spheres to construct one corn particle would have slowed their simulation significantly, thus

356 increasing computation time. The friction coefficients of this corn particle model were used to 
predict the flow patterns of the discharging particles from a silo (Gonzalez-Montellano et al. 2011). Then, they applied this modified corn particle model to study the pressure distributions, bulk density distributions, and flow properties during filling and emptying of silos (GonzalezMontellano et al. 2012a, 2012b).

\section{Wheat}

Wheat is a highly irregularly shaped kernel whose shape representation for simulation purposes is challenging; the presence of a crease makes it difficult to develop a particle with identical spheres. Studies have reported using wheat kernels in 2-D to investigate the flow of wheat in a mixed-flow grain dryer (Iroba et al. 2011a; 2011b; Mellman et al. 2011; Weigler et al. 2012). Monosized spherical particles were used to model the grain dryer in 2D using PFC 2D software. Iroba et al. (2011a) indicated that using multiple spheres would make the simulation time longer, whereas using non-spherical particles would be more difficult to model and would require more advanced algorithms. Because of the disc shape of the 2-D particles in the simulation, however, bridging between particles occurred at the bottom discharge device of the grain dryer, which did not happen during experiments. Iroba et al. (2011a, 2011b) explained that because the long and ellipsoidal shape of wheat kernels can orient in different directions during discharge, flow can be enhanced, and bridging did not occur in the experiment. Spherical particles (discs) tend to form bridges even though orientation is the same in all directions. To overcome bridging of particles during simulation, the fixed part of the discharge device was vibrated. In the subsequent simulations, the authors used non-spherical particles represented by a 2-D ellipsoidal clump consisting of five circular elements (Weigler et al. 2012). The clumps were assumed to have the same material properties as wheat, which were adapted from Markauskas et al. (2010). The DEM model indicated that using non-spherical particles (2-D ellipsoidal clumps) 
can predict the real flow pattern, but disc-shaped particles did not produce the expected dynamic angle of repose that typically formed under the air ducts.

Keppler et al. (2012) predicted the velocity distribution of wheat kernels in a mixed-flow dryer with 3-D wheat kernels using EDEM software. The wheat particle was represented by a clump of three spheres. Although the particles used in EDEM were slightly bigger than actual particles, the velocity prediction was nearly accurate. To compare the performance of different particle models, Sarnavi et al. (2013) simulated 3-D wheat kernels using three types of particle models: (1) spherical, (2) 4-spheres, and (3) 8-spheres using the PFC3D software. They compared the performance of the particle models with two contact models (linear vs. nonlinear) in predicting the angle of internal friction and cohesion of wheat. They found that the single spherical particle model, using both linear and nonlinear contact models, performed better in the simulations than the multi-sphere models. Although different particle models have been used to simulate wheat kernels, the studies clearly demonstrate that 3-D particle models have higher accuracy in predicting the bulk behavior of wheat than a 2-D approach. The results do not, however, confirm the best number of spheres to use to represent a single wheat kernel. This could be because of the complicated shape of wheat kernels; the number of spheres should be approximated by trials depending on the computation time and prediction accuracy required.

\section{Rice}

Rice's ellipsoidal shape is similar to wheat, but the absence of a crease in rice makes it easier to approximate the rice particle shape. A 2-D circular disc approach was used by Sakaguchi et al. (2001) to model rice kernels in the shaking separation process using their own DEM codes (Sakaguchi et al. 1994). The authors obtained good agreement between the simulation and experiment with respect to the wave-like behavior of the grain assembly and the macroscopic 
separation behavior of rice. Markauskas and Kačianauskas (2011) modeled rice kernels by creating an ellipsoid using 11 spheres. They compared two rice particle models, with rolling friction coefficients of zero and 0.3, using their own DEM code (Kačianauskas et al. 2010). These particle models were used to simulate the filling and discharge flow and piling of the kernels. The particle model with rolling friction produced a pile shape that better corresponded to the actual pile. On the other hand, the particle model without rolling friction showed higher particle mobility, resulting in a spread of particles rather than a pile. A 7-sphere particle model was used by Jiang and Qiu (2011) to simulate the impact behavior of rice kernels. The rice particle modeled was an ellipsoid with a 3.5-mm half major axis and a 1.8-mm half minor axis. The authors implemented this rice model in EDEM software and studied the impact of rice particles on the impact board of an inclined elevator head. Simulations predicted the experimental results with high accuracy up to a certain mass of rice that impacts the board. A 3D rice model was also used by Li et al. (2012) to simulate the material motion in an air-andscreen cleaning device. The authors separated rice kernels and straws using a coupled DEM and computational fluid dynamics (CFD) model. The rice grain was represented in EDEM by a spheroid that is $6 \mathrm{~mm}$ long with a 1.6-mm radius of rotation. The short straw was represented by a cylinder $30 \mathrm{~mm}$ long by $4 \mathrm{~mm}$ diameter. These models were used to study the effect of inlet airflow velocity in terms of the longitudinal velocity, vertical height, and cleaning loss of rice kernels and short straws. The coupled CFD-DEM model predicted the air-screen cleaning process by describing the movement of particles on the screen surface. Coupling CFD with DEM is a recent advancement in particle modeling that will be useful in the grain processing industry for prediction of various handling and processing operations. 


\section{Rapeseed}

Rapeseed is the second leading source of vegetable oil and protein meal in the world next to soybean (USDA ERS 2013); thus, its processing and handling optimization are important to the industry. Bulk compressive loading of rapeseeds was modeled by Raji and Favier (2004a) using a single sphere particle model. They found a slight difference in the initial particle positions between the experiment and simulation, although strain intervals were calculated at the same porosity values. This was an early attempt to model rapeseeds, and the authors extended the use of this single sphere particle model to simulate rapeseed, soybean, and palm-kernel for bulk compression (Raji and Favier 2004b). Later, other researchers also modeled rapeseed using a single sphere particle model to simulate the free fall and impact of rapeseeds against a flat surface (Wojtkowski et al. 2010). The authors used two different contact models, an elastoplastic contact model for dry seeds by Thornton and Ning (1998) and a viscoelastic contact model for wet seeds by Kuwabara and Kono (1987). Parafiniuk et al. (2013) simulated rapeseeds as single spheres to predict flow through a horizontal orifice. The experimental mean radii and standard deviation values were used to develop the single sphere model. The authors used EDEM software and applied the contact models used by Wojtkowski et al. (2010) for dry and wet rapeseeds. Parafiniuk et al. (2013) concluded that the contact models reproduced experimental results for slow particle flow but needed the improvement of including dissipation for higher particle flow rates. Wiącek and Molenda (2011) studied the influence of the moisture content of rapeseeds on the physical properties of grain bedding during uniaxial compression testing using single sphere particle models. Results indicated that the mechanical response of a granular assembly subjected to uniaxial compression is significantly affected by the moisture content of kernels. Both the simulations and experiments revealed differences in the elasticity and the stress transmission within rapeseed assemblies at various grain moisture contents. 

using 2-D circular discs. They used circular elements with size uniformly distributed between 1.8 and $2.2 \mathrm{~mm}$. Numerical simulations were performed using a non-commercial DEM code (Wassgren 1997) to determine the influence of three different levels of standard deviations in the coefficient of interparticle friction to the bulk behavior in a direct shear test. Particle interaction in the normal direction was simulated using a linear viscoelastic model, whereas the tangential direction was expanded to include a frictional element. Variability in the interparticle friction was found to influence markedly the stress-strain characteristic during the initiation of motion, whereas the strength of the assembly (or steady state value of stress) remained constant.

\section{Grain Coproducts}

Grain undergoes different processing methods during conversion into products and coproducts. The particle characteristics of products derived from grain are generally controlled; but particle characteristics are not uniform because the bulk contains particles with different 462 sizes, shapes, and chemical compositions. The challenge in modeling coproduct is in shape representation using spheres. For example, distillers dried grains with solubles (DDGS), a coproduct from corn-to-ethanol processing, contains a mixture of fiber, starch, and protein components that vary in size and shape. Clementson (2010) modeled the flow and segregation of DDGS using single sphere particle model in EDEM with the Hertz-Mindlin (no-slip) contact model. The geometric mean diameter of actual DDGS ranged from 0.87 to $1.01 \mathrm{~mm}$, but the researchers used bigger particles because small particles required longer simulation time in DEM; the log-normal bimodal distribution of these particles was kept similar to the actual particle size distribution. The author found that the magnitude of changes in discharge rates in 471 the experiments were not the same as in the simulation, and the numerical simulation predicted 
472 the same flow patterns as observed during funnel flow but not mass flow experiments. DEM has

473 not been widely used to predict the bulk behavior of coproducts from the grain-based food and

474 feed industry, partially because of the computational load from the higher number of spheres

475 required to obtain accurate shape representation.

\section{Modeling Grain Handling Operations}

477 Bulk behavior of cereal grains, oilseeds, and their products vary based on the quantity,

478 environmental factors, method of processing, and handling equipment used. The grain handling

479 and processing operations that have been modeled using DEM were subdivided into processes

480 dealing with free-flowing grain, such as filling and emptying of silos, and confined grain, such as

481 storage and compression.

482

483

484

485

486

487

488

489

490

491

492

493

\section{GRAN PostharVEST OPERATIONS Modeled OR STUdied USING DEM}

- Free-flowing grain

- Filling and discharge of silo

- Bulk behavior during grain conveying

- Grain cleaning and separation

○ Impacting grain kernels

- Confined grain

○ Silo probing

○ Compression

○ Shear testing

- Grain drying

Table 2 summarizes the model and references associated with these postharvest processing. 


\section{MODELING FREE-FLOWING GRAIN}

\section{Filling and Discharge of Silo}

Due to the complexity of physical and chemical parameters, hopper flow of grain and grain products usually encounters challenges such as ratholing, arching, caking, etc. Use of discharge aids in grain-based food and feed industries is a common practice to achieve uniform flow of material from hoppers and silos. DEM is increasingly applied to simulate bulk flow characteristics of grain and products for better bin design and process optimization.
Different grain filling approaches have been used to simulate grain storage systems.

Progressive filling is the more common method used in DEM simulation where particles are generated continuously, whereas in en masse filling, all particles are generated simultaneously, thus reducing computation time. In en masse filling, particles are allowed to fall under gravity until a static equilibrium is reached. Gonzalez-Montellano et al. (2012a) used the en masse filling approach for glass beads and corn kernels filling in a silo. Particles were deposited rapidly on top of each other, leading to many particles being trapped by the others without having dissipated their initial energy. During emptying, the movement of the material diluted these effects, and the observed pressures were similar to the expected pattern (Gonzalez-Montellano et al. 2012a). If the en masse method is used in simulations, prediction errors should be taken into account when studying pressures during filling of silos.

Gonzalez-Montellano et al. (2012b) improved their simulations by using a modified particle model for corn (Gonzalez-Montellano et al. 2011) and the progressive method of filling a silo (Gonzalez-Montellano et al. 2012a) from their previous work. Results highlighted a difference in the vertical distributions of pressure between corn and glass beads. During both filling and discharge, the peak pressure at the silo-hopper transition was much higher for corn than for glass beads. Pressure values also fluctuated less for corn. For horizontal pressure distribution during 
filling and at any time during the discharge of corn, maximum horizontal pressure was in the central region of the silo walls then slowly decreased toward the corners. This result was the same for glass beads, except that the distributions were less stable over time. In both models, the velocity profile at the center was greater than at the walls. For corn, the distribution of the bulk density in the vertical section was not as random as with glass beads. These researchers demonstrated DEM's usefulness in studying the behavior of granular materials in silos and hoppers and the degree of detailed information that could be obtained from simulations.

Chung and Ooi (2008b) simulated silo discharge by emptying corn through a circular orifice of a flat-bottom silo unloading onto a flat surface. Although the purpose of the study was to examine the influence of gravity on a granular solid, the terrestrial aspects of experiments closely simulated earth-bound processes using DEM. DEM simulation showed that the mass flow rate decreases as gravity decreases, with a corresponding increase in discharge time. The simulation also correlated with Beverloo's relationship that the mass flow rate is proportional to the square root of the gravitational force. In addition to corn discharge parameters, DEM also predicted reasonably the angle of repose of corn discharged from the silo (Chung and Ooi 2008b).

Mass flow rate and size of hopper outlet opening influence discharge of granular materials. Coetzee and Els (2009a) studied the discharge of corn kernels from a glass rectangular silo in two dimensions using PFC2D. Two silo openings were used in this study. The authors found that the corn particles modeled as clumps composed of two discs could reasonably predict the flow patterns observed during experiments. The results indicated that a 2-D clump particle model had higher accuracy in predicting the flow of corn through a larger silo opening where the flow was less restricted. Accuracy of DEM simulations depend on the particle models and the particle 
540 parameter values used in the simulations. In this study, the two disc particle model could have 541 influenced the prediction accuracy.

542 Monitoring the density of material that flows from hoppers or bins is one method used to 543 evaluate segregation. Clementson (2010) used DEM to predict the bulk density of DDGS 544 particles during funnel flow and mass flow from hoppers. The hopper half angles used were 33 545 degrees for the mass flow and 65 degrees for funnel flow. DEM predicted a funnel flow for 546 DDGS that was observed during experiments. The results reported by Clementson (2010) 547 supported the hypothesis that the heterogeneity of DDGS does not facilitate true mass flow, 548 irrespective of the hopper design.

549 DEM can be used to predict bulk density after filling a silo in addition to flow pattern and 550 discharge rate. González-Montellano et al. (2011) used corn kernels and glass beads in EDEM 551 simulations to model silo filling and discharge. For corn, three successive DEM models were 552 tested to identify the coefficients of interparticle and particle-wall friction. High interparticle 553 friction led to low bulk densities after the silo filling, which agreed with Boac et al.'s (2010) 554 results in simulated bulk density tests. High interparticle friction also increased the discharge 555 time. For glass beads, the velocity profile was qualitatively similar to corn but showed a more 556 fluctuating velocity profile. This result may be explained by the development of crystalline 557 packing configurations when single sphere particles were used (Chung and Ooi 2008a; 558 Gonzalez-Montellano et al. 2011). For discharge rates, results for the glass beads showed wider 559 fluctuation than those for corn kernels, which was a consequence of the relatively larger ratio 560 between particle size and silo opening used for glass beads (0.24) than for corn (0.17). 561 An axi-symmetric multi-sphere approach is a recent development that could be used to 562 develop particle models for irregularly shaped cereal grains. Markauskas and Kačianauskas 
563 (2011) used this approach to simulate the filling and discharge of rice from a small-plane wedge564 shaped hopper with a rectangular orifice. The authors simulated the angle of repose of the pile of 565 rice after its discharge from the hopper and modeled friction effects on the flow of rice through 566 an orifice. To model the friction effects, two rice particle models, with and without rolling 567 friction, were used. The researchers found that rolling friction must be taken into account to 568 avoid artificial local rotation of particles when using axi-symmetric multi-sphere particle models 569 to represent elongated, irregularly shaped particles. Numerical results provided quantitative 570 evidence of increased rolling friction owing to geometric deviations of the particle shape from 571 the axi-symmetric geometry. Simulations with zero rolling friction in the model resulted in a 572 lower angle of repose and discharge time compared with experimental values. The authors also 573 investigated the rotational energy of particles inside the hopper using both models (Markauskas 574 and Kačianauskas 2011). The rolling friction practically suppressed local spin, whereas the 575 perpendicular rotation occurred because of the collective particle arrangement. The authors 576 showed the effects of rolling friction to rotational behavior of the particles and that neglecting 577 the rolling friction led to increased capability of particles to rotate by falling on the pile.

578 The effect of moisture content on the mass flow rate of rapeseed from a silo was modeled by 579 Parafiniuk et al. (2013), who verified the applicability of the elastoplastic model for dry seeds 580 and the viscoelastic model for wet seeds adapted from Wojtkowski et al. (2010) in DEM 581 simulations. Simulation results revealed that the proposed contact models reproduced the 582 experimental results for slower rate of particle flow. At higher flow rates (or larger openings), 583 however, the dissipation of energy led to higher noise in the force simulated on the silo bottom 584 than indicated by experimental results. This discrepancy was higher in simulations where the 585 elastoplastic contact model (for dry seeds) was used. In DEM simulations, mass flow rates of dry 
and wet seeds did not differ if the mass flow rates were calculated as a sum of masses of particles falling into the receiving container per time unit, but differences in the mass flow rates of dry and wet rapeseeds were observed if calculated using the sum of vertical forces exerted by particles on walls and floor of receiving container. The authors did not include cohesion parameters in particle models, which resulted in the differences between predictions and experimental results.

The major concern when using DEM to study bin pressures is that it assumes rigid silo walls in the simulations (Gonzalez-Montellano et al. 2012b). This results in overprediction of the horizontal distribution of normal pressure at the central positions on the walls. GonzalezMontellano et al. (2012b), after continued efforts to simulate grain bins using DEM, recommended that hybrid models combine DEM and the finite element method (FEM) to compensate for DEM's limitations. DEM allows a more accurate simulation of the dynamic behavior of the granular material itself, and FEM will allow flexible walls to be included, thus yielding a complete model.

\section{Bulk Behavior During Grain Conveying}

Shear zone theory was applied by Coetzee and Els (2009a) to simulate bucket filling using DEM. The authors used a rig geometry that resembled a dragline bucket, which was pulled in the drag direction by a set of ropes but with freedom of motion in all other directions, based on the Shear Zone Theory developed by Rowlands (1991). DEM can accurately predict the filling process of a bucket or scoop, the force acting on the bucket, and the fill rate. During the experiments, the flow regimes as predicted by the Shear Zone Theory (Rowlands, 1991) were also observed. DEM predicted these different flow zones (Coetzee 2009a, 2009c), and the authors recommended that knowledge of the flow zones can be used to optimize buckets in terms of fill rate, bucket force, and bucket wear. 
Grain commingling is an unintentional introduction of a different grain type during typical

610

611

612

613

614

615

616

617

618

619

620

621

622

623

624

625

626

627

628

629

630

631 handling operations that directly reduces the level of purity in grain that enters an elevator facility. Three approaches address commingling during grain handling: (1) ignore it, (2) identitypreserve (IP) the grain in dedicated containers, and (3) segregate or handle the IP grain in nondedicated facilities. Due to limited scientific data on grain commingling in normal handling operations, it is not possible to predict the level of purity that could be achieved with the third, less expensive approach (Boac 2010). Boac et al. (2012) simulated grain commingling in a pilotscale grain elevator boot using DEM models and evaluated the tradeoffs of computational speed versus accuracy for 3D and quasi-2D boot models. Experimental data from the pilot-scale bucket elevator showed that the average cumulative commingling was comparable to the values for fullsize bucket elevator legs. To avoid overprediction, the 3D model was refined to account for the sudden surge of particles during entry and corrected for the effective dynamic gap between the bucket cups and the boot wall. Comparison of predicted average commingling of five quasi-2D boot models with reduced control volumes showed that the quasi-2D (5.6 times the particle diameter) model provided the best option in terms of computation time; it reduced computation time by $72 \%$ to $74 \%$ compared with the $3-\mathrm{D}$ model. Results of this study are being applied to study the commingling of infested and sound kernels (wheat and corn) in bucket elevator boot systems.

\section{Grain Cleaning and Separation}

The macroscopic behavior of paddy and brown rice during shaking separation was modeled by Sakaguchi et al. (2001) on an oscillating inclined separation plate using a 2-D DEM model. The grain kernels were represented as circular elements using the model developed by Sakaguchi et al. (1994). In the DEM simulation, the indents on the separation plate were modeled using 
632 virtual walls. Particle exit from an indent was modeled as removal of a virtual wall when the

633 particle-wall contact exceeded a threshold value. There was good agreement between the results

634 of the simulation and the experiment in terms of the macroscopic separation behavior of the rice.

635 The experimental observations such as segregation caused by upward movement of paddy rice

636 relative to brown rice and the shearing of the grain bed to accumulate paddy rice near the lower

637 end of the shaker box were also predicted by the DEM simulation. The time required to achieve

638 maximum separation of brown and paddy rice was the same in both experiment and simulation.

639 In the simulation, the circular particles moved closer to the lower end of the shaker than in the

640 experiment, which was due to the ease of rotation of the circular elements. However, the

641 simulation showed the same wave-like behavior of the grain assembly as in the experiment. The

642 authors concluded that a simple DEM model using 2-D circular particles and virtual walls was

643 effective and can be done with reasonable computation times. The model will allow further

644 investigation of the separation mechanism and exploration of the effects of different physical and

645 process parameters on the efficiency of grain separation in shaking separators.

646 Separation mechanism of grain kernels on sieves is a dynamic process that requires

647 consideration of various particle parameters such as size, shape, density, loading rate, and other

648 factors. Li et al. (2002) used a 2-D transient model to calculate the motion of discrete soybean

649 and mustard seed particles on sieves using DEM. The authors studied the influence of particle

650 bed depth on undersize particle segregation in an inclined vibrating screen. In the DEM

651 simulation, the sieving screen was modeled to be made of vibrating circular particles (smaller

652 than the kernels) with properties of the sieving wires. The numerical simulation indicated that at

653 a particle bed depth of about 5 times the size of the large particles and 12 times the size of the

654 screen apertures, most undersize particles segregated to the screen surface. The undersize 
655

656

657

658

659

660

661

662

663

664

665

666

667

668

669

670

671

672

673

674

675

676

677

particles also passed through the apertures within about $40 \%$ of the sieve length at the front section of the screen. For this particle bed depth, the screen length was long enough to ensure the highest screening efficiency, $100 \%$ separation, which means no undersize particle passed over and joined the overflow of large particles at the end of the screen. The authors concluded that for a screening system involving granular materials, the critical feeding rate needed to achieve the most efficient screening process can be determined using DEM simulation. Li et al. (2003) extended this study to mathematically investigate the particulate motion of polyethylene pellets on an inclined screening chute using DEM.

The coupled DEM-CFD approach has been used recently to predict the solid interaction with fluids. Li et al. (2012) used a 3-D coupled DEM-CFD model to study the effects of inlet airflow velocity on the kernels and short straw's longitudinal velocity and vertical height and the cleaning loss in an air-and-screen cleaning device. The rice grain represented by a spheroid and the short straw by a cylinder were generated in EDEM and allowed to fall on an inclined vibrating screen. The CFD portion of the coupling model used the Eulerian-Eulerian model in FLUENT (ANSYS Inc., Canonsburg, PA). The authors used Hertz-Mindlin contact model to simulate particle-particle and particle-screen (wall) collisions. Through the coupled DEM-CFD approach, the authors found that the length of the screen can be shortened if impurity content is lower. The coupled DEM-CFD modeling approach also could be used to improve the design of combine harvesters because the model accurately predicts the particle movement in air.

\section{Impacting of Grain}

The impact of grain as it falls on a flat surface influences breakage characteristics, friction, and coefficient of restitution. Wojtkowski et al. (2010) proposed that different models have to be used to predict the impact of grain kernels depending on moisture content. The researchers also 
678 indicated that to determine a correct contact model, the ratio of the fall time to the rise time (TR)

679 for the contact force-time characteristics should be considered. For TR $>1$, the authors

680 recommended the viscoelastic model, whereas the elastoplastic model should be applied for

$681 \mathrm{TR}<1$.

682 Another application of DEM in investigating the impact of grain kernel on a surface was

683 reported by Jiang and Qiu (2011). The authors studied the effects of particle mass and the normal 684 contact force between a rice particle and the impact board of an inclined elevator during flow of 685 rice. Rice kernels were represented as ellipsoids composed of seven spheres in EDEM, and 686 celluloid was used as the material for the impact board to study the effect of elevator belt speeds 687 of $0.5 \mathrm{~m} / \mathrm{s}$ to $1.0 \mathrm{~m} / \mathrm{s}$ on bulk flow. The authors found that the normal contact force between the 688 flowing rice particles and the impact board increased as the belt speed increased, but belt speed 689 had no effect on tangential contact force. There was a good linear relationship between the rice 690 particle mass and the normal contact force when the rice particle mass was from 0.18 to $0.54 \mathrm{~kg}$. 691 The authors also concluded that the retention stage (i.e., from the time when the normal contact 692 force is less than $30 \%$ of the maximum normal force to when it became zero) during impact was 693 not beneficial to grain mass flow measurement. Qiu et al. (2012) extended this study to include 694 the elevator belt speed of $1.5 \mathrm{~m} / \mathrm{s}$ and the effect of sliding during impact.

695

696

697

698

699 700

\section{ModELING Confined GRAIN}

\section{Silo Probing}

Managing grain quality in a grain handling facility involves sampling the grain from the incoming truck and testing it for quality. To assess quality, incoming bulk grain in trucks or rail cars are probed using mechanical (vacuum) probes. Chung and Ooi (2006), using DEM, simulated the penetration of probes in a dense granular medium to evaluate the resistance of 
granular bulk to penetration of a moving object and the dynamic force transmission to a contact surface. The setup the authors used was comparable to a confined compression arrangement with a probe to penetrate the bulk granular materials. Glass beads and corn kernels were used in the simulations for comparison purposes. The authors found that the measured and predicted forces fluctuated during penetration into each material. The average trend was repeatable, with corn kernels giving a larger resistance to penetration than glass beads.

\section{Compression}

Oil expression by compression is a major processing operation used by grain-based oil industries. Compression of cereal grains is a complicated process to model because it involves changes in density, inner porosity/voids due to oil removal, size, and shape. By incorporating the actual physical changes in the DEM model, Raji and Favier (2004a) developed a numerical model to predict compression behavior of rapeseeds. The model was based on the actual physical changes during loading of a low-modulus viscoelastic spherical particles and the resulting change in shape that are often neglected during DEM model development. The authors avoided errors in estimating the porosity by compressing beds of rapeseeds before the seedbeds reached the oil point so the void spaces were not filled with oil. The oil point is the state at which the bulk density of the seedbed approaches the seed kernel density. When the threshold pressure is reached, the oil emerges from a seed kernel during mechanical seed-oil expression. DEM predicted the mechanical compression of oilseeds within a standard error of estimate of 0.20 , and the predicted stress-strain values were not significantly different from the experimental values. Extending the same modeling approach to canola, soybean, and palm-kernel, Raji and Favier (2004b) validated their approach of using low-modulus viscoelastic spherical particles for DEM simulations. Raji and Favier (2004a, b) concluded that DEM is a useful tool to study the behavior 
724 of deformable soft particulates and the outputs from modeling could be used to design and

743 for glass beads.

744 Moisture content is a principal factor that influences the compression, size reduction, and modify oil expression process machinery.

The effects of materials' different shapes during compression were investigated by Chung and Ooi (2006, 2008a), who simulated the confined compression of spherical (glass beads) and nonspherical (corn kernels) particles. The confined compression test simulation was designed to investigate the mechanical response of a granular material under confined compression and the load transfer to the containing walls. The applied vertical load, vertical displacement, vertical force transmitted to the bottom platen, and force transmitted to the walls were measured, and the material properties for silo design, the lateral pressure ratio, and the bulk wall friction were also evaluated. The findings from these studies indicated that accurate representation of particle shape may not be necessary for prediction of kernels under compression because capturing the key linear dimensions of a particle may be adequate. DEM results indicated that glass spheres, with their tendency to spin more than non-spherical particles, were more sensitive to initial packing arrangement as influenced by the particle generation method. Irregular particles such as corn kernels were not sensitive to particle spacing as affected by the particle generation method. Interparticle friction affected the loading for the containing walls for corn kernels but not for glass beads; this result was attributed to the significant difference in particle stiffness between two particles. Reducing the contact friction allowed more contacts to reach limiting friction for corn, thus resulting in a larger lateral pressure ratio and a smaller load on the bottom platen than handling behavior of bulk cereal grains. Understanding the effects of moisture on compression 746 through modeling was initiated by Wiącek and Molenda (2011). The authors used EDEM 
747 software with rapeseeds represented as single spheres with $1.9 \mathrm{~mm}$ diameter and used the 748 physical properties obtained from the literature (Wiącek, 2008). The load responses of rapeseed 749 subjected to uniaxial confined compression quantified at moisture contents of $7.5 \%, 9 \%$, and $75012 \%$ and were compared with experimental data. The authors observed that the DEM predicted a 751 softer response for the spherical assembly of rapeseeds compared with the experimental 752 observations. Although the model responses deviated from the actual values, this study 753 illustrated the possibility of using DEM to predict the mechanical behavior of granular materials 754 of biological origin.

755 Interparticle friction and particle stiffness also influenced the bulk response of grain kernels in DEM simulations under confined compression. Chung and Ooi (2008b) found that reduction of 757 particle stiffness by a few orders can provide a huge computational advantage, with secondary 758 effects on the load transmission in a quasi-static assembly. The researchers also found that 759 interparticle friction has an effect on the loading of containing walls in simulating confined 760 compression of corn kernels but not of glass beads. For corn kernels, reduced contact friction allowed more contacts to reach limiting friction, resulting in a larger lateral pressure ratio and a smaller load on the bottom of the confined structure.

Modeling the compression of grain has been used to calibrate material properties for DEM simulations (Coetzee and Els 2009a, 2009b) and to determine parameter values of cohesionless corn kernels. Coetzee and Els (2009a) calibrated particle stiffness using confined compression tests (also called oedometer tests) by applying stress to corn kernels along the vertical axis at low compression rates $\left( \pm 2 \mathrm{~mm} \mathrm{~min}^{-1}\right)$. Numerical simulation of 2-D corn kernels indicated that the internal friction angle depended on particle stiffness and the particle friction coefficient. Results of the confined compression test showed that the simulated macro or bulk stiffness is a linear 
function of the particle stiffness; thus, particle stiffness can be determined through the confined compression test. This study showed that DEM simulation could enable determination of particle properties to enhance understanding of the bulk behavior of cereal grains.

\section{Shear Testing}

DEM was used to examine the influence of the friction coefficient between two sliding particles on the shear behavior of an assembly of rapeseeds in 2-D systems (Molenda et al. 2011). The authors first measured the interparticle friction coefficients for metal plates, pea, wheat, and rapeseeds. Then they simulated the direct shear test using 2-D DEM models. The authors found that the degree of variation of the coefficient of interparticle friction did not influence the final value of shear strength at steady state flow; however, the level of standard deviation of the coefficient of interparticle friction markedly influenced the shear path (or shearstrain characteristics) at the initiation of motion.

The effects of moisture content on shear testing were simulated by Sarnavi et al. (2013). They modeled the strength properties of stored wheat kernels at different moisture contents using the Jenike method of direct shear tests (ASTM 2006). The research group implemented linear and nonlinear models. Three types of particle models were used to create kernels by a multi-sphere approach: (1) spherical, (2) 4-spheres, and (3) 8-spheres. The simulation of bulk behavior was strongly affected by the interparticle interactions and particle shape representation in modeling. Linear models are more capable of representing the variation in strength properties with moisture content than nonlinear models. In general, both linear and nonlinear models have an equal chance of correctly predicting strength properties of the wheat assembly. Spherical grain models best simulated wheat kernels in bulk properties tests. Both the values of internal angle of friction and apparent cohesion have about a 70\% chance of prediction by the DEM model. 


\section{GRAIN DRYING}

Although grain is considered free-flowing during grain drying, the dense arrangement of the particles inside the grain dryer make them behave like confined particles. Iroba et al. (2011a, b) examined the physical phenomena that control particle flow in mixed-flow dryers (MFDs). They investigated the residence time distribution (RTD), particle vertical velocity profiles, and particle trajectories using PFC2D. Simulation results were validated with experiments using a semitechnical dryer test station with a transparent Plexiglas front wall. Experiments were conducted with moist wheat as a bed material, with an average moisture content of $18 \%$ wet basis (w.b.) and a bulk density of $783 \mathrm{~kg} \mathrm{~m}^{-3}$. Colored tracer particles were employed in the residence time analysis in the mixed-flow dryer (MFD) to detect particle flow inhomogeneity and design deficit. Simulation results showed that the DEM model adequately predicted particle flow during drying. Through DEM simulation, it was understood that two flow regimes exist in MFDs, the near-wall region and the central region. Particles at the near-wall region had lower particle velocity, whereas the central region had high particle velocity. Wall friction dominated the particle flow near-wall region and had a large effect on the bulk particle movement, whereas particle-particle forces were dominant in the central region. Kernels passing through the MFD have different vertical velocities, thus resulting in different residence times. The presence of two different flow regimes will affect overall dryer capacity and drying efficiency. Kernels flowing at lower velocities may be over-dried, while those moving at high velocities may be under-dried. The authors concluded that the present design of MFDs did not provide adequate cross-mixing, with the effect of the half air ducts dominant on the sidewalls. Consequently, the current design may lead to broad moisture content distribution at the outlet (inhomogeneous drying) with the risk of product quality deterioration during subsequent storage. This study underlined the importance of 
updated MFD design, such as the need to adjust the size and positions of the half air ducts. Although the 2-D DEM model predicted the residence time distributions and the flow patterns, improvements in the approach are needed to map velocity profiles. To depict the grain drying process accurately, numerical simulation should also account for the shrinkage of kernels during drying because this shrinkage alters the particle properties.

To improve the prediction of drying process using DEM, Mellman et al. (2011) modeled the effects of design elements and air duct arrangements on MFDs. The authors articulated the same findings as Iroba et al. (2011a, b) regarding the RTD in mixed-flow grain dryers. Simulation and experimental results showed that the DEM can adequately predict the main features of particle flow. The half air ducts at the sidewalls obstructed the free flow of grain, resulting in the long tail of the RTD. The studies indicated that the diagonal duct arrangement showed a more even grain moisture and temperature distribution than the horizontal duct arrangement. The airflow distribution in the grain bed in the diagonal arrangement was considered degraded, however, because of the dead zones, which were not flushed by the drying air, in the MFD. The authors concluded that grain bulk and particle moisture content as well as grain temperature distributions fluctuate strongly over the cross-section of the dryer, resulting in inhomogeneous drying. The analysis displayed deficits in the present design of MFDs, namely the arrangement and allocation of the air ducts.

Due to variations in grain properties, dryer design, and drying parameters, optimizing dryer design and understanding particle movement inside the dryer is of continued interest researchers as well as industry. The influence of dryer walls and air ducts on particle velocity distribution in an MFD was investigated by Keppler et al. (2012), who modeled the effects of particle-wall friction, air duct apex angle, and wall angle on the vertical direction of particle velocity 
distribution. The effects of different construction modifications for more even vertical grain particle velocity distribution were analyzed using DEM. The authors found from experiments and simulations that the sidewalls have a strong impact on grain flow, causing segregation; these were similar to the findings by Iroba et al. (2011a). Both studies indicated that segregation caused big differences in the residence time of single grain portions and caused uneven drying.

Weigler et al. (2012) extended the work of Iroba et al. (2011a, b) and Mellman et al. (2011) by investigating the particle and airflows in MFDs using DEM and CFD. The particle flow behavior of wheat in the traditional MFD was simulated using PFC2D. Two different particle representations of wheat, spherical and ellipsoidal, were studied and compared when simulating particle flow. A diagonal air duct arrangement led to dead zones in airflow. Airflow through the grain bed was simulated using CFD, applying the commercial software ANSYS CFX (Release 14.0, ANSYS, Inc., Canonsburg, Penn.). The airflow domain in the dryer apparatus was discretized by generating a finite volume grid employing the software ANSYS ICEM (ANSYS, Inc., Canonsburg, Penn.). The authors found that over- and under-drying occurred in traditionally designed mixed-flow dryers because of unfavorable air duct arrangements; core flow of particles due to the wall friction effect and the half air ducts fixed at the sidewalls, characterized by retarded flow at the dryer walls and a fast flow region in the center; and dead zones in airflow, resulting in uneven airflow, grain flow, and drying conditions over the cross-section. They recommended a new dryer design with the airflow distribution adjusted to the particle flow distribution. In regions with higher particle velocities, higher air velocities should be provided. The sidewalls of the dryer should be inclined, and the half air ducts should be removed. Researchers also added that future design development would require a tool that couples the 
airflow characteristics with the particle flow characteristics, including the heat and mass transfer, such as coupled CFD and DEM simulation.

Weigler et al. (2013) used the model they developed for MFDs (Weigler et al. 2012) to study the flow of grain in the process of designing an efficient MFD using PFC2D. The particle flow was studied by tracing the differently colored kernels through the transparent sidewall of the dryer. Based on the observations, the authors developed a new MFD geometry that results in uniform drying of kernels. The greatest advantage of using DEM modeling techniques in grain drying is the ability to study the grain velocity distribution within the dryer as affected by constructional modifications. This will be of great interest to industry because understanding grain behavior within the dryer allows analysis of drying without requiring an expensive prototype.

\section{A Case Study}

In this case study, the commingling of two types of grain in a bucket-type grain elevator boot system is considered based on Boac et al. (2012). Previous research in commercial elevator equipment (Ingles, et al., 2003; 2006; Ingles, 2005) showed large variations between and within facilities for commingling of grain lots, which can greatly increase the number of experiments necessary to make widely-applicable inferences. However, DEM was used in this case study to model the commingling in a grain elevator boot system and avoid the time and expense of many more experiments.

A 3-D computer-aided design (CAD) drawing (DS SolidWorks Corp., Concord, Mass.) of the pilot-scale bucket elevator leg and boot geometry (model B3, Universal Industries, Inc., Cedar Falls, Iowa) was imported in EDEM 2.3. Grain commingling in the pilot-scale boot was simulated using 3-D and quasi-2-D DEM models. Simulations were performed at $20 \%$ Rayleigh 
time step. The Hertz-Mindlin no-slip model (DEM Solutions, 2013) was implemented as the contact model for all simulations.

Two types of soybeans with different intrinsic properties were colored red and yellow in the simulation to illustrate their difference. The particle model developed by Boac et al. (2010) for soybeans was used. Red soybeans were allowed to flow inside the grain elevator boot geometry. The grain elevator leg (composed of bucket cups) was allowed to run for $15 \mathrm{~s}$ of simulation time, until the red soybeans stabilized as the residual grain at the bottom of the boot. With red soybeans as the residual grain, yellow soybeans were generated in the simulation and allowed to accumulate in the left-hand side (LHS) hopper for $15 \mathrm{~s}$ before opening the slide gate. Yellow soybeans were then continuously run in the boot for approximately 8 min in simulation time (Figure 3a).

The same simulation procedure was followed for a quasi-2-D DEM model using a periodic boundary and domain width equivalent to 5.6 times the particle diameter (Figure $3 \mathrm{~b}$ ). The total particle mass of red and yellow soybeans was determined from each bucket cup in all simulations. Predicted average commingling data were computed, plotted at each time interval, and compared with experimental data. Figure 4 shows that the predicted average commingling from 3-D and quasi-2-D DEM models of the boot closely matched the experimental data, especially after the flow has stabilized after $100 \mathrm{~s}$. The quasi-2-D (5.6d) model reduced simulation run time by $72 \%$ to $74 \%$ compared to the 3-D model, with both models being run on the same workstation (Table 4). This case study showed that grain commingling in a bucket elevator boot system can be simulated with both 3-D and quasi-2-D DEM models, giving results that agreed with experimental data. 


\section{Application of DEM in Other Food Engineering Operations}

907 Postharvest operations in any food engineering applications are complex and modeling has

908 proved to be effective for prediction, process calculation and process design purposes. Ho et al.

909 (2013) suggested that parallel multiscale modeling, with a complete understanding of the

910 structural aspect of food material, will be the best approach for analyzing and designing food

911 processing systems.

912 In specific, fresh horticultural crop produce are difficult to model due to their non-uniformity

913 in size and shape and for their higher vulnerability to changes in surface and textural

914 characteristics during handling and transport (Ambaw et al. 2013). Delele et al. (2010) developed

915 a combined DEM and computational fluid dynamics (CFD) model to analyze the airflow during

916 cooling through stacks of boxes with horticultural produce. DEM was used to generate random

917 stacking of spheres in the box. Cooling was simulated at different heights of the stack with

918 different diameter spheres. The results indicate that DEM helped identify that random filling has

919 less influence on the air flow resistance than other factors such as confinement ratio, size,

920 porosity, and box vent hole ratio. Through this coupled DEM-CFD approach, the flow profile in

921 individual pores could be analyzed that could not be done through porous media approaches.

922 Van Zeebroeck et al. (2006 ab) applied DEM to study impact damage in apples during

923 transport and handling. The authors used the nonlinear Kuwbara and Kono contact force model

924 and the parameters were derived experimentally. The model findings were validated using a

925 shaking box approach of vibrating apples in an electro-hydraulic shaker. Though the authors

926 predicted the bruising damage with reasonable accuracy, multi-impact bruise surfaces and the

927 bruise volume could not be predicted. For vibration damage, the Kuwabara and Kona contact

928

model predicted the condition of apple as influenced by fruit properties and mechanical 
parameters such as vibration frequency and stack height. Further, the model accurately predicted the existence of damage chains within the apple stack.

\section{Summary and Conclusions}

Existing literature that used DEM to simulate postharvest handling and processing, limited to grain and its coproducts, was reviewed. The soft-sphere approach of DEM was commonly used to develop these grain and food processing industry process simulations. The advantage of softsphere models was their capability of handling multiple particle contacts, which are of importance when modeling bulk grain systems. The deformations that a grain kernel undergoes during handling and processing were used to calculate elastic, plastic, and frictional forces between particles, and the motion of particles was described by Newton's laws of motion.

Particle models varied with the type of grain. For near-spherical kernels such as soybean and rapeseed, single sphere particle models predicted particle behavior with greater accuracy. For non-spherical kernels such as rice, wheat, and corn, particle representation using a multi-sphere approach reduced specific simulation errors, but increased simulation time and computational load because of the higher number of contact points requiring force and deformation calculation at each contact point. To avoid this excess computation time problem, most researchers have used single sphere models and had reasonable success in predictions. Rotation of the singlesphere particles must be properly described, however, because these particles rotate more easily in the simulation than observed in experiments. Thus, the rolling friction coefficient is an important component when using spherical particle models to simulate non-spherical kernels.

Depending on the software used, both linear and non-linear (Hertz-Mindlin) contact models have been used effectively to study grain handling and processing operations. 
DEM simulations have been used in different grain processing environments, such as those

952 dealing with free-flowing grain and with confined grain, for optimizing processes and to improve

953 equipment design. In general, DEM has adequately simulated postharvest processing of grain

954 and grain coproducts. In some processes, such as the analysis of discharge from a silo and design

955 of grain dryers, coupling DEM with computational fluid dynamics is recommended for better

956 predictions. Although DEM has been increasingly used to study grain kernel processes, it has not

957 been widely applied. The huge variation in particle characteristics such as size, shape, surface

958 roughness, density, friction coefficients, composition, and other factors could be hindering the

959 use of DEM. Computational cost also limits DEM application; specifically, most of the particles

960 in grain-based food industries are smaller, which leads to higher computation time. Development

961 of precision particle models could help spur adoption of this numerical modeling concept and

962 optimize process and equipment design in the grain handling and processing industry.

963 ACKNOWLEDGEMENTS

964 This is contribution no. 14-278-J from the Kansas State University Agricultural Experiment 965 Station. 


\section{References}

Ambaw A, Delele MA, Defraeye T, Ho QT, Opara LU, Nicolai BM, Verboven P (2013) The use of CFD to characterize and design post-harvest storage facilities: past, present and future. Computers and Electronics in Agriculture 93: 184-194

ASTM. 2006. Standard test method for shear testing of bulk solids using the Jenike shear cell. D6128. American Society for Testing and Materials, West Conshohocken, PA

Boac JM (2010) Quality changes, dust generation, and commingling during grain elevator handling. Ph.D. Dissertation. Kansas State University, Manhattan, Kansas

Boac JM, Casada ME, Maghirang RG, Harner JP (2010) Material and interaction properties of selected grains and oilseeds for modeling discrete particles. Transactions of the ASABE 53(4):1201-1216

Boac JM, Casada ME, Maghirang RG, Harner JP (2012) 3-D and quasi-2-D discrete element modeling of grain commingling in a bucket elevator boot system. Transactions of the ASABE 55(2):659-672

Boukouvala F, Gao Y, Muzzio F, Ierapetritou MG (2013) Reduced-order discreter element method modeling. Chemical Engineering Science 95: 12-26

Campbell CS (2006) Granular material flows - an overview. Powder Technology 162:208-229

Chung YC, Ooi JY, Favier JF (2004) Measurement of mechanical properties of agricultural grains for DE models. In: 17th ASCE Engineering Mechanics Conference. American Society of Civil Engineers, Newark, Delaware 
987

988

989

990

991

992

993

994

995

996

997

998

999

1000

1001

1002

1003

1004

1005

1006

1007

1008

1009

Chung YC, Ooi JY (2006) Confined compression and rod penetration of a dense granular medium: discrete element modeling and validation. In: Wu W, Yu HS (eds.) Modern trends in geomechanics. pp. 223-239. Springer, Berlin

Chung YC, Ooi JY (2008a) Influence of discrete element model parameters on bulk behavior of a granular solid under confined compression. Particulate Science and Technology 26(1):83-96

Chung YC, Ooi JY (2008b) A study of influence of gravity on bulk behaviour of particulate solid. Particuology 6(6):467-474

Clementson CL (2010) The granulometric heterogeneity of distillers dried grains with solubles (DDGS) and its effect on the bulk physical and chemical properties. Ph.D. Thesis. Purdue University, West Lafayette, Indiana

Coetzee CJ, Els DNJ (2009a) Calibration of discrete element parameters and the modelling of silo discharge and bucket filling. Computers and Electronics in Agriculture 65(2):198212

Coetzee CJ, Els DNJ (2009b) Calibration of granular material parameters for DEM modelling and numerical verification by blade-granular material interaction. Journal of Terramechanics 46(1):15-26

Coetzee CJ, Els DNJ (2009c) The numerical modelling of excavator bucket filling using DEM. Journal of Terramechanics 46(5):217-227

Coetzee CJ, Els DNJ, Dymond GF (2010) Discrete element parameter calibration and the modelling of dragline bucket filling. Journal of Terramechanics 47(1):33-44

Cundall PA (1988a) Computer simulations of dense sphere assemblies. In: Satake M, Jenkins JT (eds.) Micromechanics of granular materials. pp. 113-23. Elsevier, Amsterdam 
1010 Cundall PA (1988b) Formulation of a three-dimensional distinct element method. Part I: A 1011 scheme to detect and represent contacts in a system composed of many polyhedral

1012

1013

1014

1015

1016

1017

1018

1019

1020

1021

1022

1023

1024

1025

1026

1027

1028

1029

1030 blocks. International Journal of Rock Mechanics and Mining Sciences and Geomechanics Abstracts 25(3):107-116

Cundall PA, Hart RD (1989) Numerical modeling of discontinua. In Mustoe GGW, Henriksen M, Huttelmaier HP (eds) Proceedings of the 1st U.S. Conference on Discrete Element Methods. CSM Press, Golden, Colorado

Cundall PA, Strack ODL (1979) A discrete numerical model for granular assemblies. Geotechnique 29(1):47-65

de Bruyn, JR (2012) When does a granular material behave like a continuum fluid? Journal of Fluid Mechanics 704:1-4

Delaney G, Inagaki S, Aste T (2007) Fine tuning DEM simulations to perform virtual experiments with three dimensional granular packings. In: Aste Y, Di Matteo T, Tordesillas A (eds) Granular and Complex Materials. pp. 141-168. World Scientific

Delele MA, Tijskens E, Atalay YT, Ho QT, Ramon H, Nicolai BM, Verboven, P (2008) Combined discrete element and CFD modelling of airflow through random stacking of horticultural products in vented boxes. Journal of Food Engineering 89(1): 33-41

DEM Solutions (2013) EDEM 2.5 User Guide. DEM Solutions, Ltd., Edinburgh, UK Dewicki G (2003) Bulk material handling and processing - numerical techniques and simulation of granular material. Bulk Solids Handling: International Journal of Storing and Handling Bulk Materials 23(2):110-113 
1031 Di Renzo A, Di Maio FP (2004) Comparison of contact-force models for the simulation of

1032

1033

1034

1035

1036

1037

1038

1039

1040

1041

1042

1043

1044

1045

1046

1047

1048

1049

1050

1051

1052

1053 collisions in DEM-based granular flow codes. Chemical Engineering Science 59(3):525541

Di Renzo A, Di Maio FP (2005) An improved integral non-linear model for the contact of particles in distinct element simulations. Chemical Engineering Science 60(5):1303-1312

FAO (2013) Zae mays L. Food and Agriculture Organization of the United Nations, Rome, Italy

Favier JF, Abbaspour-Fard MH, Kremmer M, Raji AO (1999) Shape representation of axisymmetrical, non-spherical particles in discrete element simulation using multi-element model particles. Engineering Computations 16(4):467-480

Ferellec JF, McDowell GR (2010) A method to model realistic particle shape and inertia in DEM. Granular Matter 12(5):459-467

Fortin J, Millet O, de Saxce G (2004) Numerical simulation of granular materials by an improved discrete element method. International Journal for Numerical Methods in Engineering 62:639-663

Ghaboussi J, Barbosa R (1990) Three-dimensional discrete element method for granular materials. International Journal for Numerical and Analytical Methods in Geomechanics $14(7): 451-472$

González-Montellano C, Ramirez A, Gallego E, Ayuga F (2011) Validation and experimental calibration of 3D discrete element models for the simulation of the discharge flow in silos. Chemical Engineering Science 66(21):5116-5126

González-Montellano C, Ramirez A, Fuentes JM, Ayuga F (2012a) Numerical effects derived from en masse filling of agricultural silos in DEM simulations. Computers and Electronics in Agriculture 81:113-123 
1054 González-Montellano C, Gallego E, Ramirez-Gomez A, Ayuga F (2012b) Three dimensional 1055 discrete element models for simulating the filling and emptying of silos: Analysis of 1056 numerical results. Computers and Chemical Engineering 40:22-32

1057 González-Montellano C, Fuentes JM, Ayuga- Tellez E, Ayuga F (2012c) Determination of the 1058 mechanical properties of maize grains and olives required for use in DEM simulations. 1059 Journal of Food Engineering 111(4):553-562

1060 Jiang G, Qiu B (2011) Discrete element method simulation of impact-based measurement of 1061 grain mass flow. In Proceedings of the 2011 International Conference on Computer 1062 Distributed Control and Intelligent Environmental Monitoring 5747847:419-422

Ho QT, Carmeliet J, Datta AK, Defraeye T, Delele MA, Herremans E, Opara L, Ramon H, Tijskens E, Sman Rvd, Liedekerke PV, Verboven P, Nicolai BM (2013) Multiscale modeling in food engineering. Journal of Food Engineering 114: 279-291

Hocking G (1992) The discrete element method of analysis of fragmentation of discontinua. Engineering Computation 9(2):145-155

Hogue C (1998) Shape representation and contact detection for discrete element simulations of arbitrary geometries. Engineering Computations 15(3):374-390

Hoomans BPB, Kuipers JAM, Briels WJ, Van Swaaij WPM (1996) Discrete particle simulation of bubble and slug formation in a two-dimensional gas-fluidized bed: A hard-sphere 1076 approach. Chemical Engineering Science 51(1):99-118 
1077

1078

1079

1080

1081

1082

1083

1084

1085

1086

1087

1088

1089

1090

1091

1092

1093

1094

1095

1096

1097

1098

Hustrulid AI (1998) Transfer station analysis. Paper presented at the 1998 SME Annual Meeting, Orlando, Florida

Hustrulid AI, Mustoe GGW (1996) Engineering analysis of transfer points using discrete element analysis. Paper presented at the 1996 SME Annual Meeting, Phoenix, Arizona

Ingles MEA (2005) Identity preservation of grain in elevators. Unpublished PhD dissertation. Kansas State University Department of Biological and Agricultural Engineering, Manhattan, Kansas

Ingles MEA, Casada ME, Maghirang RG (2003) Handling effects on commingling and residual grain in an elevator. Transactions of the ASAE 46(6):1625-1631

Ingles MEA, Casada ME, Maghirang RG, Herrman TJ, Harner JP III (2006) Effects of grainreceiving system on commingling in a country elevator. Applied Engineering in Agriculture 22(5):713-721

Iroba KL, Mellman J, Weigler F, Metzger T, Tsotsas E (2011a) Particle velocity profiles and residence time distribution in mixed-flow grain dryers. Granular Matter 13(2): 159-168

Iroba KL, Weigler F, Mellman J, Metzger T, Tsotsas E (2011b) Residence time distribution in mixed-flow grain dryers. Drying Technology 29(11):1252-1266

Isik E (2007) Some Engineering Properties of Soybean Grains. American Journal of Food Technology 2:115-125

Itasca (2008) PFC3D Particle flow code in 3 dimensions: Theory and background. Itasca Consulting Group, Minneapolis, Minn. 40pp

Jean M, Moreau JJ (1991) Dynamics of elastic or rigid bodies with frictional contact: numerical methods. Publications du L.M.A. 124:9-29 
1099 Kačianauskas R, Maknickas A, Kačeniauskas A, Markauskas D, Balevičius R (2010) Parallel 1100 discrete element simulation of poly-dispersed granular material. Advances in Engineering $1101 \quad$ Software 41(1):52-63

1102 Keppler I, Kocsis L, Oldal I, Farkas I, Csatar A (2012) Grain velocity distribution in a mixed 1103 flow dryer. Advanced Powder Technology 23(6):824-832

1104 Kuwabara G, Kono K (1987) Restitution coefficient in a collision between two spheres. Japanese Journal of Applied Physics 26(8):1230-1233 screen cleaning device. Computers and Electronics in Agriculture 88:111-119

Li H, Li Y, Gao F, Zhao Z, Xu L (2012) CFD-DEM simulation of material motion in air-and-

Li J, Webb C, Pandiella SS, Campbell GM (2002) A numerical simulation of separation of crop seeds by screening - effect of particle bed depth. Food and Bioproducts Processing: Transactions of the Institution of Chemical Engineers, Part C 80(2):109-117

1111 Li J, Webb C, Pandiella SS, Campbell GM (2003) Discrete particle motion on sieves - a numerical study using the DEM simulation. Powder Technology 133(1-3):190-202 for 'sandpiles' composed of spherical particles. Powder Technology 160(3):219-228

Lin X, Ng TT (1997) A three-dimensional discrete element model using arrays of ellipsoids.

$1116 \quad$ Geotechnique 47(2):319-329

1117 LoCurto GJ, Zhang X, Zarikov V, Bucklin RA, Vu-Quoc L, Hanes DM, Walton OR (1997)

1118 Soybean impacts: experiments and dynamic simulations. Transactions of the ASAE

$1119 \quad$ 40(3):789-794

1120 Lu M, McDowell GR (2007) The importance of modelling ballast particle shape in the discrete 1121 element method. Granular Matter 9(1-2):69-80 
1122 Markauskas D, Kačianauskas R (2011) Investigation of rice grain flow by multi-sphere particle

1123 model with rolling resistance. Granular Matter 13(2):143-148

1124 Markauskas D, Kačianauskas R, Džiugys A, Navakas R (2010) Investigation of adequacy of

1125 multi-sphere approximation of elliptical particles for DEM simulations. Granular Matter

$1126 \quad 12(1): 107-123$

1127 Mellman J, Iroba KL, Metzger T, Tsotsas E, Mészáros C, Farkas I (2011) Moisture content and

1128 residence time distributions in mixed-flow grain dryers. Biosystems Engineering 109(4):

1129

1130 Metzger MJ, Glasser BJ (2013). Simulation of the breakage of bonded agglomerates in a ball

1131 mill. Powder Technology 237: 286-302

1132 Miller GF, Pursey H (1955) On the partition of energy between elastic waves in a semi-infinite

1133 solid. Proceedings of the Royal Society of London Series A: Mathematical and Physical

$1134 \quad$ Sciences 233(1192):55-69

1135 Mindlin RD (1949) Compliance of elastic bodies in contact. Journal of Applied Mechanics

$1136 \quad 16: 259-268$

1137 Mindlin RD, Deresiewicz H (1953) Elastic spheres in contact under varying oblique forces.

1138 Transactions of ASME, Series E. Journal of Applied Mechanics 20:327-344

1139 Mishra BK (2003) A review of computer simulation of tumbling mills by the discrete element

1140 method: Part I - contact mechanics. International Journal of Mineral Processing 71(1-

$1141 \quad 4): 73-93$

1142 Molenda M, Horabik J, Lukaszuk J, Wiącek J (2011) Variability of intergranular friction and its

1143 role in DEM simulation of direct shear of an assembly of rapeseeds. International

$1144 \quad$ Agrophysics 25(4): 361-368 
1145 O’Sullivan C (2011a) Particle-based discrete element modeling: Geomechanics perspective. Internation Journal of Geomechanics 11(6):449-464

1147 O’Sullivan C (2011b) Particulate discrete element modelling: A geomechanics perspective. Spon

$1148 \quad$ Press, New York, NY

1149 Parafiniuk P, Molenda M, Horabik J (2013) Discharge of rapeseeds from a model silo: physical

$1150 \quad$ testing and discrete element method simulations. Computers and Electronics in

$1151 \quad$ Agriculture 97: 40-46

1152 Potyondy DO, Cundall PA (2004) A bonded-particle model for rock. International Journal of Rock Mechanics and Mining Sciences 41(8):1329-1364

Qiu B, Jiang G, Yang N, Guan X, Xie J, Li Y (2012) Discrete element method analysis of impact action between rice particles and impact-board. Transactions of the Chinese Society of Agricultural Engineering 28(3):44-49 (Chinese)

Raji AO, Favier JF (2004a) Model for the deformation in agricultural and food particulate materials under bulk compressive loading using discrete element method. Part I: Theory,

Raji AO, Favier JF (2004b) Model for the deformation in agricultural and food particulate materials under bulk compressive loading using discrete element method. Part II: Compression of oilseeds. Journal of Food Engineering 64(3):373-380

Remy B, Khinast JG, Glasser BJ (2009) Discrete element simulation of free-flowing grains in a four-bladed mixer. AIChE Journal 55(8):2035-2048

Rowlands, JC (1991) Dragline bucket filling. Ph.D. Thesis. University of Queensland, Queensland, Australia 
1167 Sakaguchi E, Kawakami S, Tobita F (1994) Simulation on flowing phenomena of grains by 1168 distinct element method. Eur. Ag. Eng. Paper No. 94-G-025. Ag. Eng. '94, Milano

1169 Sakaguchi E, Suzuki M, Favier JF, Kawakami S (2001) Numerical simulation of the shaking 1170 separation of paddy and brown rice using the discrete element method. Journal of $1171 \quad$ Agricultural Engineering Research 79(3):307-315

1172 Sarnavi HJ, Mohammadi AN, Motlagh AM, Didar AR (2013) DEM model of wheat grains in 1173 storage considering the effect of moisture content in direct shear test. Research Journal of

1175 Theuerkauf J, Dhodapkar S, Jacob K (2007) Modeling granular flow using discrete element 1176 method - from theory to practice. Chemical Engineering 114(4):39-46

1177 Thornton C, Ning Z (1998) A theoretical model for the stick/bounce behaviour of adhesive, 1178 elastic-plastic spheres. Powder Technology 99(2):154-162

Ting JM, Khwaja M, Meachum L, Rowell JD (1993) An ellipse based discrete element model for granular materials. International Journal for Numerical and Analytical Methods in Geomechanics 17(9):603-623

Tsuji Y, Tanaka T, and Ishida T (1992) Lagrangian numerical simulation of plug flow of cohesionless particles in a horizontal pipe. Powder Technology 71(3):239-250

1184 USDA ERS (2013) Oil Crops Yearbook. U.S. Department of Agriculture Economic Research

1185 Service, Washington, D.C. http://www.ers.usda.gov/data-products/oil-crops$1186 \quad$ yearbook.aspx\#.UupiItJdUS4

1187 Van Zeebroeck M, Tijskens E, Dintwa E, Kafashan J, Loodts J, De Baerdemaeker J, Ramon H 1188 (2006 a) The discrete element method (DEM) to simulate fruit impact damage during 
transport and handling: Model building and validation of DEM to predict bruise damage of apples. Postharvest Biology and Technology 41: 85-91

Van Zeebroeck M, Tijskens E, Dintwa E, Kafashan J, Loodts J, De Baerdemaeker J, Ramon H (2006 b) The discrete element method (DEM) to simulate fruit impact damage during transport and handling: Case study of vibration damage during apple bulk transport. Postharvest Biology and Technology 41: 92-100

Vu-Quoc L, Zhang X, Walton OR (2000) A 3-D discrete-element method for dry granular flows of ellipsoidal particles. Computer Methods in Applied Mechanics and Engineering 187(3-4):483-528

Walton OR (1983) Particle - dynamics calculations of shear flow. In: Jenkins JT and Satake M (eds) Micromechanics of granular materials: new models and constitutive relations. pp. 327-338. Elsevier, Amsterdam

Wassgren CR (1997) Vibration of granular materials. Ph.D. Thesis. California Institute of Technology, Pasadena, California

Weigler F, Scaar H, Mellmann J (2012) Investigation of particle and air flows in a mixed-flow dryer. Drying Technology 30(15):1730-1741

Weigler F, Mellmann J, Franke G, Scaar H (2013) Experimental studies on a newly developed mixed-flow dryer. Drying Technology 31: 1736-1743

Wiącek J (2008) Discrete element modeling of quasi-static effects in grain assemblies. PhD Thesis, Institute of Agrophysics, PAS, Lublin, Poland

Wiącek J, Molenda M (2011) Moisture-dependent physical properties of rapeseed - experimental and DEM modeling. International Agrophysics 25(1):59-65 
1211 Wightman C, Moakher M, Muzzio FJ, Walton OR (1998) Simulation of flow and mixing of

1212

1213

1214

1215

1216

1217

1218

1219

1220

1221

1222

1223

1224

1225

1226

1227

1228 particles in a rotating and rocking cylinder. Journal of American Institute of Chemical Engineers 44(6):1266-1276

Williams JR, Hocking G, Mustoe GGW (1985) The theoretical basis of the discrete element method. NUMETA '85 Numerical Methods in Engineering, Theory and Applications. Balkema, Rotterdam, The Netherlands

Williams JR, Pentland AP (1989) Superquadrics and modal dynamics for discrete elements in concurrent design. In: $1^{s t}$ U.S. Conference on the Discrete Element Method, Golden, Colorado

Wojtkowski M, Pecen J, Horabik J, Molenda M (2010) Rapeseed impact against a flat surface: physical testing and DEM simulation with two contact models. Powder Technology 198(1):61-68

Zhou YC, Xu BH, Yu AB, Zulli P (2001) Numerical investigation of the angle of repose of monosized spheres. Physical Review E: Statistical, Nonlinear, and Soft Matter Physics 64(2):213011-213018

Zhu HP, Zhou ZY, Yang RY, Yu AB (2007) Discrete particle simulation of particulate systems: theoretical developments. Chemical Engineering Science 62(13):3378-3396 